\title{
História da equiparação do Colégio Pedro II à condição de Instituto Federal:
}

\section{Legislação e estrutura atual}

History of Colegio Pedro III equating to the status of Federal Institute: Legislation and current structure

Historia de la condición de Instituto Federal del Colegio Pedro II: Legislación y estructura actual

Recebido: 24/04/2021 | Revisado: 01/05/2021 | Aceito: 01/05/2021 | Publicado: 15/05/2021

\author{
Ricardo Dias das Neves \\ ORCID: https://orcid.org/0000-0003-2503-5560 \\ Colégio Pedro II, Brasil \\ E-mail: rdneves1@yahoo.com
}

\begin{abstract}
Resumo
Este artigo é baseado no período de 12 anos entre 2008 (ano em que a Rede Federal foi criada) e 2020. O Colégio Pedro II foi fundado em 1837, e suas atividades vão desde a educação infantil até a pós-graduação Stricto Senso. A Lei n ${ }^{\circ}$ 11.892 de 2008 criou os Instituto Federais, e sua redação foi atualizada pela Lei no 12.677 de 2012, para incluir o Colégio Pedro II na Rede Federal de Educação Científica, Profissional e Tecnológica. A Lei 12.677/12 conservou a denominação tradicional "Colégio Pedro II", equiparando-o, contudo, à condição de Instituto Federal de Educação, Ciência e Tecnologia. Este artigo enfoca os aspectos legais desta equiparação, explicando conceitos jurídicos e comentando os principais dispositivos da legislação pertinente. Além de integrar o ordenamento jurídico brasileiro, esta legislação também contribuiu para a edificação da história do Colégio Pedro II e da educação profissional no Brasil.
\end{abstract}

Palavras-chave: Educação profissional; Instituto federal; Legislação; História; Ensino.

\begin{abstract}
This article is based on the 12-year period between 2008 (the year in which the Federal Network was created) and 2020. Colégio Pedro II was founded in 1837, and its activities range from early childhood education to Stricto Senso graduate school. Law No. 11,892 of 2008 created the Federal Institute, and its wording was updated by Law No. 12,677 of 2012, to include Colégio Pedro II in the Federal Network of Scientific, Professional and Technological Education. Law 12.677/12 retained the traditional name "Colégio Pedro II", however, equating it to the condition of Federal Institute of Education, Science and Technology. This article focuses on the legal aspects of this assimilation, explaining legal concepts and commenting on the main provisions of the relevant legislation. In addition to integrating the Brazilian legal system, the legislation also contributed to the development of Colégio Pedro II and professional education in Brazil. Keywords: Professional education; Federal institute; Legislation; History; Teaching.

\section{Resumen}

Este artículo se basa en el período de 12 años comprendido entre 2008 (año en que se creó la Red Federal) y 2020. El Colégio Pedro II fue fundado en 1837, y sus actividades van desde la educación infantil hasta la escuela de posgrado Stricto Senso. La Ley N ${ }^{\circ} 11.892$ de 2008 creó el Instituto Federal, y su redacción fue actualizada por la Ley $\mathrm{N}^{\circ} 12.677$ de 2012, para incluir al Colegio Pedro II en la Red Federal de Educación Científica, Profesional y Tecnológica. La Ley 12.677 / 12 retuvo el nombre tradicional de "Colégio Pedro II", sin embargo, equiparándolo a la condición de Instituto Federal de Educación, Ciencia y Tecnología. Este artículo se centra en los aspectos legales de esta asimilación, explicando conceptos legales y comentando las principales disposiciones de la legislación pertinente. Además de integrar el sistema legal brasileño, la legislación también contribuyó al desarrollo del Colégio Pedro II y la educación profesional en Brasil.
\end{abstract}

Palabras clave: Educación profesional; Instituto federal; Legislación; Historia; Ensenãnza.

\section{Introdução}

A Rede Federal de Educação Profissional, Científica e Tecnológica (Rede Federal) foi criada pela Lei 11.892/2008. A Rede Federal é formada por trinta e oito Institutos Federais de Educação Profissional, Científica e Tecnológica (IF), dois Centros Federais de Educação Tecnológica (CEFET), pela Universidade Tecnológica Federal do Paraná (UTFPr), pelo Colégio Pedro II (CP2), além de vinte e duas Escolas Técnicas vinculadas às Universidades Federais. 
O art .2ํㅡ da Lei 11.892 de 2008 descreve o conceito de Instituto Federal:

Art. $2^{\circ}$ Os Institutos Federais são instituições de educação superior, básica e profissional, pluricurriculares e multicampi, especializados na oferta de educação profissional e tecnológica nas diferentes modalidades de ensino, com base na conjugação de conhecimentos técnicos e tecnológicos com as suas práticas pedagógicas, nos termos desta Lei (Brasil, 2008, p.1).

No desenvolvimento deste artigo foram utilizadas as pesquisas de natureza qualitativa e quantitativa, com metodologia de pesquisa documental. A pesquisa documental foi realizada a partir da análise detalhada de estatutos, projetos de lei, exposição de motivos, tramitação legislativa, pareceres, regimentos e leis referentes aos Institutos Federais e ao Colégio Pedro II, consultados através dos sites destes órgãos, bem como da legislação correlata ao tema. Na pesquisa quantitativa foram analisados gráficos e quadros numéricos.

O presente texto adota como base os Princípios, Objetivos e Finalidades da EPT (Educação Profissional e Tecnológica), segundo Marise Ramos. O ensino médio integrado baseia-se no tripé do trabalho, da ciência e da cultura.

Sob as perspectivas de conferir especificidades próprias a cada uma das dimensões constitutivas da prática social que devem organizar o ensino médio de forma integrada - trabalho, ciência e cultura - que entendemos a necessidade de o ensino médio ter uma base unitária sobre a qual podem se assentar possibilidades diversas de formações específicas: no trabalho, como formação profissional; na ciência, como iniciação científica; na cultura, como ampliação da formação cultural (RAMOS, 2005, p.10, grifo nosso).

\section{História da Equiparação do Colégio Pedro II à Condição de Instituto Federal: Legislação Aplicada}

A Constituição Federal menciona o Colégio Pedro II no artigo 242, parágrafo $2^{\circ}$ : "O Colégio Pedro II, localizado na cidade do Rio de Janeiro, será mantido na órbita federal".

De acordo com o artigo $1^{\circ}$, parágrafo único, p. 1, da Lei 11.892, “As instituições mencionadas nos incisos I, II, III e V do caput possuem natureza jurídica de autarquia, detentoras de autonomia administrativa, patrimonial, financeira, didáticopedagógica e disciplinar".

O Art. $5^{\circ}$ do decreto-lei $n^{\circ} 200 / 1967$, define autarquia como:

Art. $5^{\circ}$ Serviço autônomo, criado por lei, com personalidade jurídica, patrimônio e receita próprios para executar atividades típicas de Administração Pública, que requeiram, para seu melhor funcionamento, gestão administrativa e financeira descentralizada (Brasil, 1967, p. 1).

Nas palavras de Maria Sylvia Zanella Di Pietro (2012, p. 368), autarquia é a "pessoa jurídica de direito público, criada por lei, com capacidade de auto-administração, para o desempenho de serviço público descentralizado, mediante controle administrativo exercido nos limites da lei".

Destarte, a natureza jurídica autárquica incide na forma de descentralização administrativa, por meio da personificação de um serviço removido da Administração centralizada, desempenhando atividades típicas de Estado.

As principais áreas de atuação do Colégio Pedro II são a educação básica e as licenciaturas. Estas tiveram início no ano de 2020, no campus Realengo, com oferta de 160 vagas. Conforme o Art. $4^{\circ}$-A, p. 1, da Lei 11.892 de 2008, "O Colégio Pedro II é instituição federal de ensino, pluricurricular e multicampi, vinculada ao Ministério da Educação e especializada na oferta de educação básica e de licenciaturas".

O Projeto de Lei 2.134 de 2011, de autoria do poder executivo, deu origem à Lei 12.677 de 2012. O projeto foi assinado pela então ministra do Ministério do Planejamento, Miriam Belchior e pelo então ministro da Educação, Fernando Haddad. Com a ementa "Dispõe sobre a criação de cargos efetivos, cargos de direção e funções gratificadas no âmbito do Ministério da 
Educação, destinados às Instituições Federais de Ensino, e dá outras providências", este projeto iniciou sua tramitação pela Câmara dos Deputados em 24/08/2011, sendo sancionado em 29/06/2012, pela Presidente Dilma Roussef.

Cabe ressaltar, como documento anexo ao Projeto de Lei, a seção de “Exposição de Motivos” (EM Interministerial $n^{\circ}$ 00178/2011/MP/MEC). Dentre os principais motivos que justificaram a equiparação do Colégio Pedro II à condição de Instituto Federal de Educação, Ciência e Tecnologia, consoante o PL 2.134/2011, temos: (Brasil, 2011, p. 11, grifo nosso).

Outra matéria contemplada no Anexo Projeto de Lei diz respeito à reestruturação do Colégio Pedro II. No contexto da política de expansão do ensino público pelo Governo Federal, deu-se início a um período de implantação de novas Unidades Escolares.

A expansão do Colégio Pedro II por meio da criação de novas unidades escolares e da implementação de novos cursos, bem como os esforços de ampliação de sua área de atuação com vistas à abertura de turmas de educação infantil e de cursos de pós-graduação lato e stricto sensu, acabaram por tornar imperiosa a atualização dos instrumentos legais relativos à sua ordenação e estruturação, principalmente no que se refere a pessoal. Dessa forma, estamos propondo sua equiparação aos Institutos Federais para efeito da incidência das disposições que regem a regulação, avaliação e supervisão das instituições e dos cursos de educação profissional e superior.

Todo o trabalho desenvolvido pelo Colégio Pedro II nos últimos anos, desde a criação e implantação de unidades escolares até a implementação de cursos de educação profissional, se deu sem que seu quadro de pessoal efetivo docentes e técnico-administrativos - sofresse qualquer aumento. Dessa forma, além de sua equiparação aos Institutos Federais, estamos propondo também a reestruturação de seu quadro de professores da educação básica, técnica e tecnológica e de técnico-administrativos.

\section{Estrutura Atual do Colégio Pedro II}

Nos Institutos Federais, a reitoria é responsável pela administração central, bem como a definição de diretrizes institucionais. O reitor e os diretores podem editar portarias para regulamentar decisões administrativas.

A reitoria e os campi são enquadrados como unidades autônomas nos quesitos orçamento e gestão. Reitoria e campi possuem cada um seu próprio CNPJ individualizado. O reitor atua como ordenador de despesa do orçamento da reitoria. Também, cada diretor geral atua como ordenador de despesa do campus por ele dirigido.

Com a publicação da Lei 12.677/12, as unidades escolares passaram automaticamente à condição de campi da instituição. Conforme o art. 13-B da Lei 12.677/12:

Art. 13-B. As unidades escolares que atualmente compõem a estrutura organizacional do Colégio Pedro II passam de forma automática, independentemente de qualquer formalidade, à condição de campi da instituição (Brasil, 2012, p.1).

Atualmente, o Colégio Pedro II possui aproximadamente 13 mil alunos (Quadro 1), distribuídos em 14 campi ${ }^{1}$, oferecendo cursos técnicos, integrados ao ensino médio regular.

\footnotetext{
1 Os 14 campi do Colégio Pedro II receberam as seguintes denominações (organizados por ordem alfabética): Centro, Duque de Caxias, Engenho Novo I, Engenho Novo II, Humaitá I, Humaitá II, Niterói, Realengo I, Realengo II, São Cristóvão I, São Cristóvão II, São Cristóvão III, Tijuca I e Tijuca II. Além dos campi citados, o CP2 possui também o CREIR (Centro de Referência da Educação Infantil), vinculado à Reitoria e que administra a Educação Infantil.
} 
Quadro 1 - Distribuição dos alunos do Colégio Pedro II por etapa.

\begin{tabular}{|l|c|}
\hline \multicolumn{1}{|c|}{ Etapa } & No de alunos \\
\hline Educação Infantil & 172 \\
\hline Anos Iniciais do EF & 2.845 \\
\hline Anos Finais do EF & 3.675 \\
\hline Ensino Médio Regular & 4.096 \\
\hline Ensino Médio Integrado & 736 \\
\hline Proeja & 581 \\
\hline Cursos FIC & 470 \\
\hline Pós-graduação lato sensu & 404 \\
\hline Pós-graduação stricto sensu & 140 \\
\hline \multicolumn{2}{|c|}{ Total } \\
\hline
\end{tabular}

Fonte: PDI/CP2 (2019).

De acordo com o Quadro 2, no ano de 2020, o Colégio Pedro II ofereceu 1.231 vagas no ensino técnico (integrado e subsequente) e 1.120 vagas no PROEJA, totalizando 2.351 vagas, o que corresponde a $17 \%$ do total de vagas (13.844) oferecidas pela instituição.

Quadro 2 - Quadro de vagas do Colégio Pedro II.

\begin{tabular}{|c|c|c|}
\hline Modalidade & 2019 & 2020 \\
\hline Educaçăo Infantil & 168 & 168 \\
\hline Ensino Fundamental (Anos Iniciais) & 2880 & 2880 \\
\hline Ensino Fundamental (Anos Finais) & 3740 & 3770 \\
\hline Ensino Médio Regular & 4515 & 4515 \\
\hline Ensino Técnico- Integrado & 990 & 1080 \\
\hline Ensino Técnico-Subsequente & 35 & 151 \\
\hline Proeja & 910 & 1120 \\
\hline Graduaçăo & 0 & 160 \\
\hline Totais & 13238 & 13844 \\
\hline
\end{tabular}

Fonte: PDI/CP2 (2019).

Também, conforme o Quadro 3, foram oferecidas 767 vagas na pós-graduação: 
Research, Society and Development, v. 10, n. 5, e53110515416, 2021

(CC BY 4.0) | ISSN 2525-3409 | DOI: http://dx.doi.org/10.33448/rsd-v10i5.15416

Quadro 3 - Quadro de vagas do Colégio Pedro II (Pós-graduação).

\begin{tabular}{|c|c|c|c|c|c|c|}
\hline & Modalidalte & $2 m$ & 2080 & 2021 & 202 & 2023 \\
\hline \multirow{15}{*}{ Espetialinas bo } & $\begin{array}{l}\text { fdoraplos para as Relagder } \\
\text { ftrico raclais }\end{array}$ & 50 & 45 & 45 & 45 & 5 \\
\hline & Edacacion Picomutors & 30 & 30 & 30 & 30 & 30 \\
\hline & Envino de Artes Visuais & 90 & 90 & 90 & 90 & $\infty$ \\
\hline & $\begin{array}{l}\text { Ciencies Socieis e Educoçio } \\
\text { Banice }\end{array}$ & 36 & 36 & 36 & 36 & * \\
\hline & Fdataribs Matemiatica & 36 & 36 & 36 & 36 & * \\
\hline & Envino de Ciencian e Biologin & 36 & 36 & 36 & 36 & $x$ \\
\hline & Enino de Hiutbra & 36 & 36 & 36 & 36 & * \\
\hline & Enino de Hiatória da Africa & 36 & 3f & 3 IE & 36 & $\underline{x}$ \\
\hline & $\begin{array}{l}\text { Uinguibtica e Priticas Docentes } \\
\text { em Espenhal }\end{array}$ & 36 & 36 & 36 & 36 & * \\
\hline & $\begin{array}{l}\text { Priticat Musicais na folvaglio } \\
\text { Basia }\end{array}$ & - & 30 & 30 & 30 & $\infty$ \\
\hline & $\begin{array}{l}\text { Proterama de Residencis } \\
\text { Docente. }\end{array}$ & 270 & 120 & 120 & 126 & 120 \\
\hline & Enins $\&$ O Oimica & 36 & 36 & 36 & 36 & 3 \\
\hline & $\begin{array}{l}\text { Teocies e Priticas da Geografla } \\
\text { Escoler }\end{array}$ & 36 & 36 & If & 36 & 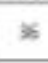 \\
\hline & $\begin{array}{l}\text { Enulas de Fisice no Educeida } \\
\text { Batice }\end{array}$ & H & 36 & 36 & 36 & * \\
\hline & 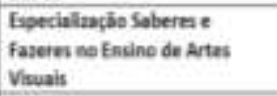 & 36 & Af & 16 & 36 & * \\
\hline \multirow{3}{*}{$\begin{array}{l}\text { Meitrado } \\
\text { Profhusional }\end{array}$} & $\begin{array}{l}\text { Edacas bo Profissiond e } \\
\text { tecosibeja (Phorfept) }\end{array}$ & 20 & 20 & 20 & 20 & 20 \\
\hline & $\begin{array}{l}\text { Metemitica em hede Necionel } \\
\text { [propman) }\end{array}$ & 36 & 36 & 36 & 36 & $x$ \\
\hline & Priticas de Educaço flánica & II & 36 & 36 & 36 & $x$ \\
\hline
\end{tabular}

Fonte: PDI/CP2 (2019).

O expressivo número de alunos matriculados no ensino fundamental (Figura 2) e no ensino médio regular do Colégio Pedro II (básico propedêutico), não se observa nos demais Institutos Federais, onde predomina o ensino técnico de nível médio.

Figura 2 - Matrículas por nível no Colégio Pedro II.

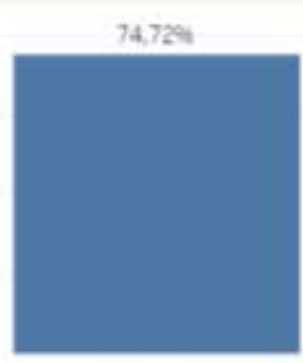

Baice Propesifutice

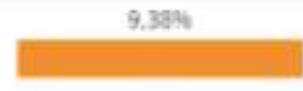

Ouabificactio Prefiasional (FIC)

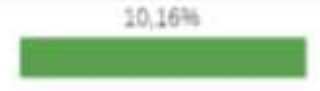

Teicutices
5.745

Pésograsuacis

Fonte: Plataforma Nilo Peçanha (2020).

O gráfico da Figura 3 esclarece o perfil e a distribuição dos cursos e oferta, com dados compilados para os Institutos Federais de todo o Brasil. O Colégio Pedro II foi excluído da composição do gráfico, para efeito de comparação. Observamos a ausência de participação na coluna de educação básica propedêutica. 
Research, Society and Development, v. 10, n. 5, e53110515416, 2021

(CC BY 4.0) | ISSN 2525-3409 | DOI: http://dx.doi.org/10.33448/rsd-v10i5.15416

Figura 3 - Distribuição por tipo de curso e oferta nos Institutos Federais

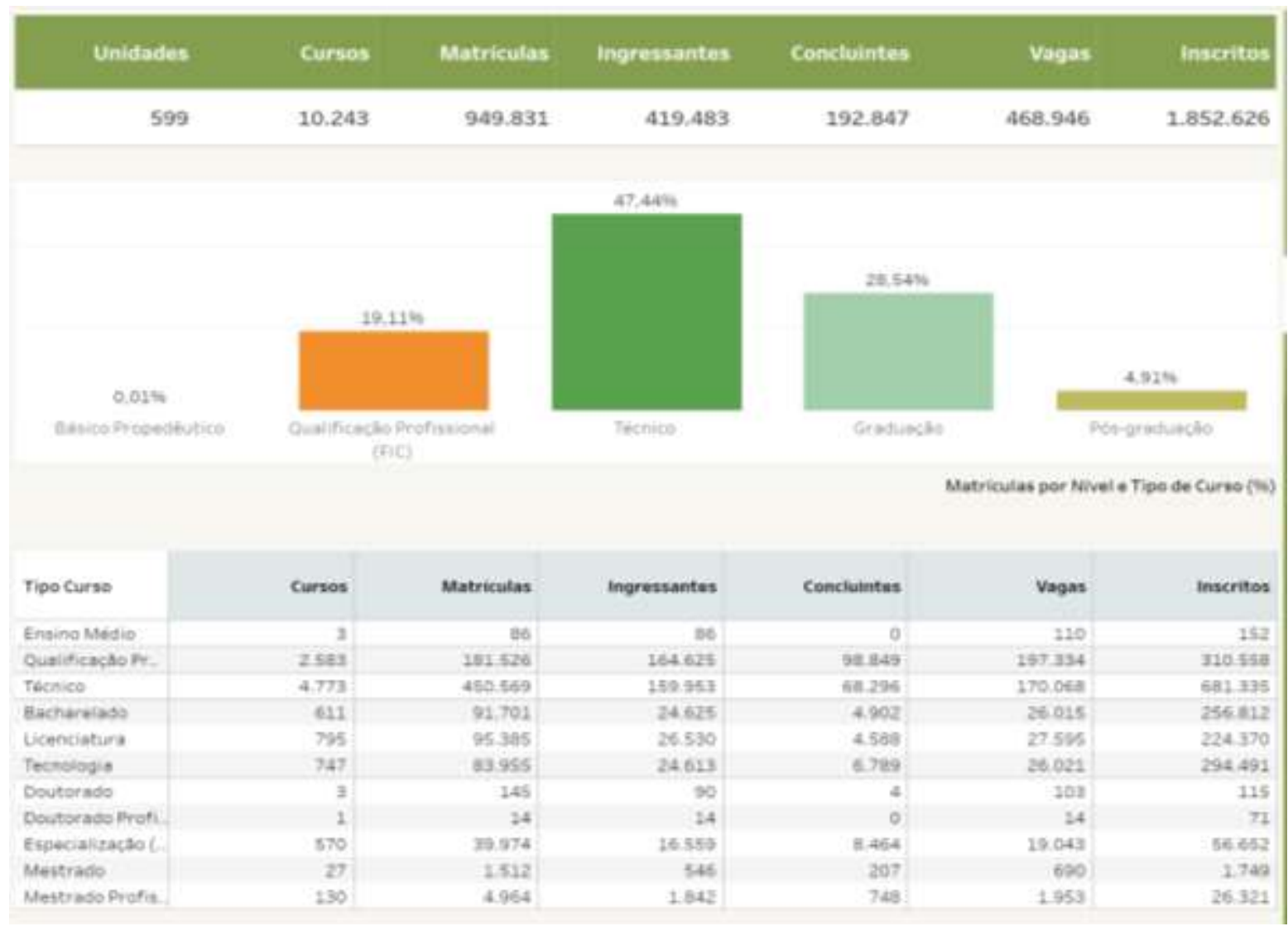

Fonte: Plataforma Nilo Peçanha (2020)

Após o enquadramento do Colégio Pedro II como Instituto Federal, no ano de 2012, o total de alunos da Pós-Graduação Stricto Senso aumentou 640\%, passando de 20 alunos em 2014, para 148 alunos, em 2018, conforme o Quadro 4.

Quadro 4 - Indicadores Acadêmicos (Pós-Graduação).

\begin{tabular}{|c|c|c|c|c|c|}
\hline \multicolumn{1}{|c|}{ Indicadores Acadêmicos - Pós-Graduação } \\
\hline Indicadores & $\mathbf{2 0 1 8}$ & $\mathbf{2 0 1 7}$ & $\mathbf{2 0 1 6}$ & $\mathbf{2 0 1 5}$ & $\mathbf{2 0 1 4}$ \\
\hline Total de alunos da Pós-Graduação Stricto Sensu & 148 & 124 & 94 & 54 & 20 \\
\hline
\end{tabular}

Fonte: Site CP2 (2018).

Com relação à titulação do corpo docente (Quadro 5), observamos que a grande maioria (74\%) possui titulação de mestre ou doutor, enquanto no quadro técnico-administrativo, predomina o título de especialista (37\%).

${ }^{2}$ FIC - Formação Inicial e Continuada. Como exemplo de cursos para Formação Inicial e Continuada, temos os cursos oferecidos pelo Colégio Pedro II no âmbito do Pronatec. 
Quadro 5 - Titulação dos docentes.

\begin{tabular}{|c|c|}
\hline \multicolumn{2}{|c|}{ Titulação do Corpo Docente - 2018 } \\
\hline Titulação & Docentes \% \\
\hline Graduação & $6,29 \%$ \\
\hline Aperfeiçoamento & $0,34 \%$ \\
\hline Especialização & $19,46 \%$ \\
\hline Mestrado & $53,35 \%$ \\
\hline Doutorado & $20,56 \%$ \\
\hline
\end{tabular}

Fonte: Site CP2 (2018).

Em termos absolutos, o Colégio Pedro II possui 928 professores com mestrado ou doutorado (Quadro 6).

Quadro 6 - Quantitativo de docentes por titulação.

\begin{tabular}{|c|c|c|c|c|c|c|}
\hline Instituiçầo & Total & Graduaçảo & Aperfeicoamento & Especializazảo & Mestrado & Doutorado \\
\hline Total & 1.405 & 220 & 6 & 251 & 672 & 256 \\
\hline CPII & 1.405 & 220 & 6 & 251 & 672 & 256 \\
\hline
\end{tabular}

Fonte: Plataforma Nilo Peçanha (2018).

O Colégio Pedro II possui 382 servidores técnico-administrativos com especialização (Quadro 7).

Quadro 7 - Titulação dos técnicos-administrativos.

\begin{tabular}{|c|c|c|}
\hline \multicolumn{3}{|c|}{ Titulação do Corpo Técnico - 2018 } \\
\hline Titulação & Técnicos & $\%$ \\
\hline Ensino Fundamental & 2 & $0,2 \%$ \\
\hline Ensino Médio / Técnico & 147 & $14,5 \%$ \\
\hline Graduação & 63 & $6,2 \%$ \\
\hline Aperfeiçoamento & 293 & $29,0 \%$ \\
\hline Especialização & 382 & $37,7 \%$ \\
\hline Mestrado & 112 & $11,1 \%$ \\
\hline Doutorado & 13 & $1,3 \%$ \\
\hline Total & 1012 & $100 \%$ \\
\hline
\end{tabular}

Fonte: Site CP2 (2018).

O Índice de Titulação do Corpo Docente (ITCD) do Colégio Pedro II, atingiu, segundo a Plataforma Nilo Peçanha (Brasil, 2019, não paginado), o nível 3,8. Este índice aproxima-se da média observada na Rede Federal, conforme dados do MEC:

O Índice de Titulação do Corpo Docente (ITCD) vem subindo constantemente, indicando a progressiva especialização acadêmica dos professores da Rede Federal. No ano de 2018, o ITCD atingiu o nível 4,0 em uma escala de 1,0 a 5,0, sendo que $80,28 \%$ dos professores possuem título de metrado ou doutorado, o que comprova o alto nível acadêmico dos professores da Rede Federal. 
Os órgãos colegiados são formados pelo Conselho Superior, de caráter consultivo e deliberativo, composto pelo Reitor e por representantes da comunidade interna e externa à instituição, e o Colégio de Dirigentes, órgão consultivo composto pelo Reitor, Pró-Reitores e Diretores Gerais. A Reitoria, órgão executivo, é composta pelo Reitor e 5 (cinco) Pró-Reitores. Os Diretores Gerais têm a responsabilidade da administração dos campi, conforme o Artigo 10 da Lei 11.892/2008:

Art. 10. A administração dos Institutos Federais terá como órgãos superiores o Colégio de Dirigentes e o Conselho Superior.

$\S 1$ As presidências do Colégio de Dirigentes e do Conselho Superior serão exercidas pelo Reitor do Instituto Federal. $\S 2$ o O Colégio de Dirigentes, de caráter consultivo, será composto pelo Reitor, pelos Pró-Reitores e pelo Diretor-Geral de cada um dos campi que integram o Instituto Federal.

§ 3 o O Conselho Superior, de caráter consultivo e deliberativo, será composto por representantes dos docentes, dos estudantes, dos servidores técnico-administrativos, dos egressos da instituição, da sociedade civil, do Ministério da Educação e do Colégio de Dirigentes do Instituto Federal, assegurando-se a representação paritária dos segmentos que compõem a comunidade acadêmica.

$\S 4 \mathrm{O}$ O estatuto do Instituto Federal disporá sobre a estruturação, as competências e as normas de funcionamento do Colégio de Dirigentes e do Conselho Superior (Brasil, 2008, p. 1).

De acordo com o Artigo 11, p. 2, da Lei 11.892/2008, a reitoria é órgão executivo, "Os Institutos Federais terão como órgão executivo a reitoria, composta por 1 (um) Reitor e 5 (cinco) Pró-Reitores"”.

A direção geral passou a ser chamada de Reitoria. Conforme o Art. 14 do Estatuto do Colégio Pedro II:

O COLÉGIO PEDRO II será dirigido por um Reitor, escolhido, em processo de consulta, pelos servidores do quadro ativo permanente (docentes e técnico-administrativos) e pelos estudantes regularmente matriculados, nomeado na forma da legislação vigente, para um mandato de quatro anos, contados da data da posse, permitida uma recondução sucessiva, nos termos do art. 12 da Lei no 11.892, de 2008 e do Decreto no 6.986, de 2009 (COLÉGIO PEDRO II, 2014, p. 2).

Nos termos do Art. 12 da Lei 11.892/2008:

Art. 12. Os Reitores serão nomeados pelo Presidente da República, para mandato de 4 (quatro) anos, permitida uma recondução, após processo de consulta à comunidade escolar do respectivo Instituto Federal, atribuindo-se o peso de 1/3 (um terço) para a manifestação do corpo docente, de 1/3 (um terço) para a manifestação dos servidores técnicoadministrativos e de 1/3 (um terço) para a manifestação do corpo discente (Brasil, 2008, p. 2, grifo nosso).

De acordo com o art $7^{\circ}$, inciso VI, alínea c, da Lei 11.892 de 2008, não existe restrição ao oferecimento de cursos de bacharelado pelos Institutos Federais:

VI - ministrar em nível de educação superior:

c) cursos de bacharelado e engenharia, visando à formação de profissionais para os diferentes setores da economia e áreas do conhecimento (Brasil, 2008, p.1, grifo nosso).

Como exemplo da amplitude de saberes dos cursos de bacharelados ministrados nos Institutos Federais, o IFRJ (Instituto

Federal de Educação, Ciência e Tecnologia do Rio de Janeiro), oferece cursos de graduação em Ciências Biológicas, Farmácia e Fisioterapia.

Em seguimento ao tema "legislação aplicada", a representação judicial do Colégio Pedro II é realizada pela Procuradoria Regional Federal da $2^{\mathrm{a}}$ Região, conforme o parágrafo único, Art. 23, do Estatuto do Colégio Pedro II:

Art. 23. A Procuradoria Jurídica vincula-se à Advocacia-Geral da União, para fins de orientação normativa e supervisão técnica, competindo-lhe executar as atividades de consultoria e assessoramento jurídico, bem como assistir às autoridades do COLÉGIO PEDRO II no controle interno da legalidade administrativa dos atos a serem praticados, inclusive examinando previamente os textos de atos normativos e os editais de licitação. 
Parágrafo único. A representação judicial da Instituição será feita pela Procuradoria Regional Federal da 2a Região (COLÉGIO PEDRO II, 2014, p. 13, grifo nosso).

De acordo com o art. 131 da Constituição Federal, "a Advocacia-Geral da União (AGU) é a instituição que, diretamente ou através de órgão vinculado, representa a União, judicial e extrajudicialmente, cabendo-lhe, nos termos da lei complementar que dispuser sobre sua organização e funcionamento, as atividades de consultoria e assessoramento jurídico do Poder Executivo" (Brasil, CF, 1988, art. 131).

A AGU exerce função essencial à Justiça, contudo não se vincula aos três Poderes que representa.

A atuação consultiva AGU se dá por meio da consultoria e do assessoramento e orientação às autoridades e dirigentes do Poder Executivo, para dar segurança jurídica aos atos administrativos que serão por eles praticados, notadamente quanto ao planejamento e execução das políticas públicas, à viabilização jurídica das licitações, contratos, convênios e acordos, à atuação em processos administrativos disciplinares, à defesa de agentes públicos perante o Tribunal de Contas da União, e, ainda, à proposição e análise de atos normativos (Emendas à Constituição, Leis, Medidas Provisórias, Decretos, Portarias e Resoluções, entre outros) (AGU, 2020, não paginado).

\section{Considerações Finais}

O Colégio Pedro II é uma instituição tradicional e centenária, que compõe a Rede Federal de Educação Profissional, Científica e Tecnológica. Sua missão institucional é: "Promover a educação de excelência, pública, gratuita e laica, por meio da indissociabilidade do ensino, da pesquisa e da extensão, formando pessoas capazes de intervir de forma responsável na sociedade" (Colégio Pedro II, 2019).

O tema desenvolvido vai ao encontro do Planejamento Estratégico do Colégio Pedro II (2019-2023), na dimensão acadêmica e pedagógica: "Disseminar a história do Colégio Pedro II de maneira a preservar a memória institucional e fortalecer os sentimentos de identidade, pertencimento e cidadania" (Colégio Pedro II, 2019).

Este artigo não pretendeu esgotar as interpretações dos assuntos nele abordados, contribuindo, contudo, para a edificação de um conjunto de saberes no âmbito do Programa de Mestrado do Colégio Pedro II.

\section{Referências}

Brasil. (2021). Constituição da República Federativa do Brasil. <http://www.planalto.gov.br/ccivil_03/constituicao/constituicaocompilado.htm>.

Brasil. (2021). Decreto $n^{\circ} 5.154$, de 23 de julho de 2004. Regulamenta o $\S 2^{\circ}$ do art. 36 e os arts. 39 a 42 da Lei no 9.394 , de 20 de dezembro de 1996 , que estabelece as diretrizes e bases da educação nacional. < http://www.planalto.gov.br/ccivil_03/_ato2004-2006/2004/decreto/d5154.htm.>.

Brasil. (2021). Lei nº 9.394, 20 de dezembro de 1996. Lei de diretrizes e bases da educação nacional. <http://www.planalto.gov.br/ccivil_03/leis/19394.htm>.

Brasil. (2021). Lei n 11.892, de 29 de dezembro de 2008. Institui a Rede Federal de Educação Profissional, Científica e Tecnológica, cria os Institutos Federais de Educação, Ciência e Tecnologia, e dá outras providências. <http://www.planalto.gov.br/ccivil_03/_Ato2007-2010/2008/Lei/L11892.htm>.

Brasil. (2021). Lei no 12.677, de 25 de junho de 2012. Dispõe sobre a criação de cargos efetivos, cargos de direção e funções gratificadas no âmbito do Ministério da Educação, destinados às instituições federais de ensino e dá outras providências. <https://www2.camara.leg.br/legin/fed/lei/2012/lei-12677-25-junho-2012613458-normaatualizada-pl.html >.

Ciavatta, Maria; Ramos, Marise. (2001). Ensino Médio e Educação Profissional no Brasil. Dualidade e Fragmentação. Brasília: Revista Retratos da Escola. p36.

Colégio Pedro II. (2019). Planejamento Estratégico. <http://www.cp2.g12.br/usingjoomla/extensions/components/contentcomponent/article-categories/9835planejamento-estrat\%C3\%A9gico-2019-2013.html>.

Colégio Pedro II. (2019). Plano de Desenvolvimento Institucional. <http://www.cp2.g12.br/images/comunicacao/2019/Outubro/pdi/1.\%20Plano\%20de\%20 Desenvolvimento\%20Institucional.pdf>.

Di Pietro, Maria Sylvia Zanella. (2012). Direito Administrativo. São Paulo: Atlas.

Frigotto, Gaudêncio; Ciavatta, Maria; Ramos, Marise. (2005). Ensino médio integrado: concepção e contradições. Cortez.

G1. (2017). População que se declara preta cresce 14,9\% no Brasil em 4 anos, aponta IBGE. <https://g1.globo.com/economia/noticia/populacao-que-se-declara- 
Research, Society and Development, v. 10, n. 5, e53110515416, 2021

(CC BY 4.0) | ISSN 2525-3409 | DOI: http://dx.doi.org/10.33448/rsd-v10i5.15416

preta-cresce-149-no-brasil-em-4-anos-aponta-ibge.ghtml.>

Instituto Brasileiro de Geografia e Estatística (IBGE). (2021). PNAD Educaçao. <https://agenciadenoticias.ibge.gov.br/agencia-sala-de-imprensa/2013-agenciade-noticias/releases/28285-pnad-educacao-2019-mais-da-metade-das-pessoas-de-25-anos-ou-mais-nao-completaram-o-ensino-medio > .

Ministério da Educação (MEC). (2021). Relatório anual de análise dos indicadores de gestão das instituições federais de educação profissional, científica e tecnológica. < http://portal.mec.gov.br/docman/julho-2021-pdf/117321-caderno-de-indicadores-2019-tcu/file>.

Ministério da Educação (MEC). (2021). PNP. Plataforma Nilo Peçanha. Brasília. <http://plataformanilopecanha.mec.gov.br/2021.html>.

Meirelles, Hely Lopes. (2013). Direito administrativo brasileiro. (39a ed.), Malheiros.

Neves, Ricardo Dias das. O Colégio Pedro II no contexto da educação profissional e tecnológica: aspectos legais. Rio de Janeiro, 2021. Dissertação (Mestrado Profissional em Educação Profissional e Tecnológica). Colégio Pedro II.

Neves et al. Colégio Pedro II: Um estudo sobre legislação e indicadores aplicados. Research, Society and Development, $10, \mathrm{e} 0210313192$.

Pacheco, Eliezer. (2011). Os Institutos Federais - Uma revolução na educação profissional e tecnológica. Moderna,

Pacheco, Eliezer. (2015). “Apresentação e Fundamentos da Proposta Político Pedagógica” In:. Fundamentos Político-Pedagógicos dos Institutos Federais: diretrizes para uma educação profissional e tecnológica transformadora. Natal: IFRN. (PP. 6-27). <ttps://memoria.ifrn.edu.br/bitstream/ handle/1044/1018 /Fundamentos\%20PolíticoPedagógicos\%20dos $\% 20$ Institutos $\% 20$ Federais $\% 20-\% 20$ Ebook.pdf?sequence=1\&isAllowed=y $>$

Pádua, E. M. M. (1997). Metodologia da pesquisa: abordagem teórico-prática. (2a ed.), Papirus.

Pereira A.S. et al. (2018). Metodologia da pesquisa científica. UFSM. https://repositorio.ufsm.br/bitstream/handle/1/15824/Lic_Computacao_MetodologiaPesquisa-Cientifica.pdf?sequence $=1$

Ramos, M. (2005). Possibilidades e desafios na organização do currículo integrado. In: Frigotto, G.; Ciavatta, M.; Ramos, M.. Ensino Médio Integrado: concepções e contradições. Cortez. 